\title{
A escrita epistolar no hospício: documento médico, documento histórico*
}

\author{
Yonissa Marmitt Wadi
}

No mundo moderno ocidental poucos são os acontecimentos que não deixam vestígios escritos. Quase tudo, em algum momento, passa por um pedaço de papel, em velocidades variadas e segundo diferentes técnicas, conforme o lugar, a hora, a possibilidade, o investimento, a disponibilidade ou as chamadas exigências legais, com suas rotinas burocráticas que disciplinam o dia-a-dia.

Acontecimentos relativos à existência de pessoas consideradas "loucas”, encontram suporte, por exemplo, nos registros em papel das instituições de seu enclausuramento, como os hospícios dos séculos XIX e XX. São destes registros, especialmente dos prontuários psiquiátricos, que emergem comumente as imagens da vida desses sujeitos, às vezes ruidosos, mas quase sempre silenciosos ou silenciados. Porém, ainda que mais raros, vestígios de sua existência podem ser encontrados em outros textos, como autobiografias, diários, poemas, bilhetes e cartas. O acesso

* Texto baseado na Tese de Doutorado “Louca pela vida: a história de Pierina”, Programa de Estudos Pós-Graduados em História, Pontifícia Universidade Católica de São Paulo, defendida em abril de 2002, sob orientação da Prof. Titular Maria Odila Leite da Silva Dias. 


\begin{tabular}{lrrrrr|l}
$R \quad E \quad V$ & I & T A & \\
LATIN O A M E RIC AN A & \\
DE PSICO PATO LO GIA & \\
F U N D A M E N T A L & \\
ano VIII, & n. 1, & mar/ 2005 & \\
\hline
\end{tabular}

a estes últimos, comumente, se dá por meio dos próprios prontuários, onde usualmente encontram-se anexados.

No início do século XX, no Hospício São Pedro de Porto Alegre (Rio Grande do Sul, Brasil), ${ }^{1}$ o termo prontuário referia-se ao conjunto de documentos acumulados na trajetória de um mesmo paciente dentro do hospital. Um prontuário, nos primeiros quarenta anos de funcionamento da instituição, de 1884 até meados da década de 1920, era composto por uma papeleta, que deveria conter os dados de identificação dos internos, as informações médicas sobre o dia-a-dia e a anotação do diagnóstico; e uma série de anexos, como requerimentos e/ou requisições de autoridades encaminhando os ditos loucos para internação, atestados de médicos que os haviam examinado antes de serem encaminhados ao hospital, atestados de admissões definitivas de pacientes e, em alguns casos, bilhetes ou cartas, de pacientes, procuradores ou familiares.

Os prontuários são documentos médicos por excelência, porém, além disto, são documentos históricos riquíssimos. Estudos variados que enfocam o saber médico, seus agentes, as instituições de sua prática, as fronteiras entre saúde e doença mental, entre outras tantas problemáticas, servem-se dos prontuários como fonte. Quando nos prontuários psiquiátricos são encontrados textos redigidos pelos próprios internos, como poemas, bilhetes, cartas, as imagens históricas se ampliam enormemente. O encontro de tais escritos descortina um leque de possibilidades de compreensão de experiências singulares, da vida vivida por sujeitos considerados loucos, que muitas vezes vai além da experiência da internação. Estas possibilidades entusiasmam historiadores, além de outros pesquisadores do social, que há algum tempo descobriram as escrituras cotidianas e práticas epistolares - diários, autobiografias, cartas... -, especialmente os das pessoas comuns, ${ }^{2}$ como fontes expressivas para abrir novos caminhos no conhecimento das sociedades humanas.

Minha própria experiência de pesquisa demonstrou a riqueza interpretativa suscitada pela descoberta de uma "escritura ordinária”, como um conjunto de cartas guardadas junto a um prontuário de uma mulher que esteve internada no Hospício São Pedro, entre 5 de julho de 1909 e 11 de maio de 1911. A camponesa

1. O Hospício São Pedro de Porto Alegre foi inaugurado em 29 de junho de 1884, sendo o primeiro hospital de alienados do Rio Grande do Sul, cuja história, a partir desse marco, tornouse correlata da construção da psiquiatria na então província. Cf. Wadi (2002a).

2. As escrituras cotidianas e práticas epistolares das pessoas comuns são chamadas também de "escrituras ordinárias ou escritos sem qualidade", pois são aquelas "que se opõem aos escritos prestigiados elaborados com vontade explícita de fazer uma 'obra’ para ser impressa”. Daniel Fabre apud Cunha (2002, p. 183). 
Pierina Cechini, ${ }^{3}$ branca, casada, filha de imigrantes italianos, nascida e criada num pequeno município encravado na parte superior da Encosta da Serra, interior do Rio Grande do Sul, tinha cerca de 28 anos quando, em julho de 1909, foi internada no Hospício São Pedro sob a suspeita de "sofrer das faculdades mentais", depois de ser indiciada em processo criminal por ter afogado sua filha pequena, cerca de três meses antes. Lá estando, escreveu três cartas e um bilhete. ${ }^{4}$ A retenção, na maioria das vezes, dos escritos dos ditos loucos e sua anexação aos prontuários como provas circunstanciais de uma dita doença, era uma prática comum nos hospitais psiquiátricos daquela época. Como um grande contra-senso, foi o que tornou possível que os “fragmentos de vida”, narrados por ela, chegassem a mim tantos anos depois.

Pierina "arquivou" sua vida nas cartas que escreveu - ao que parece ora espontaneamente, ora a pedido dos médicos - para o Juiz do Crime de Garibaldi, para sua mãe Maria, para uma enfermeira da Santa Casa de Misericórdia e para os "doutores". ${ }^{5}$ Nas cartas Pierina omitiu qualquer referência direta ao acontecimento trágico que precipitou sua escritura, ou seja, o crime e os detalhes de como o cometera, tudo já intensamente narrado ao delegado, ao promotor, ao juiz e até ao médico legista da Chefatura de Polícia, entre outros atores desta trama, como registram os documentos construídos pelos saberes, especialmente o processo criminal ${ }^{6}$ e a perícia médico-legal. ${ }^{7}$ Suponho que no contexto em que foram escritas, ou seja, interna num hospício para averiguação de sua "sanidade mental”, interessava a ela nas cartas explicar aos “doutos” as motivações do seu crime, o que tentou fazer narrando "... todo o que $\mathrm{t}$ [inha] pasado neste triste mundo...”, principalmente a partir de seu casamento, que considerava o marco inicial de sua infelicidade. ${ }^{8}$

3. Os nomes de todas as pessoas diretamente envolvidas na história de Pierina - inclusive o seu próprio - foram trocados por pseudônimos, conforme exigência do Conselho de Ética na Pesquisa do Hospital Psiquiátrico São Pedro.

4. As cartas encontram-se em: HOSPÍCIO SÃO PEDRO. Prontuário n. 38120- P.C.(APRS-Cx. 06).

5. Segundo Artières (1998, p. 11) a prática de "arquivar a vida" obedece tanto a uma injunção social - no caso de Pierina o incentivo dos médicos para que ela escrevesse sobre sua vida, “... sem pular páginas nem deixar lacunas” - quanto a uma intenção autobiográfica, e, neste caso, faz-se um acordo com a realidade, manipula-se a existência, escolhe-se alguns acontecimentos e se os ordena numa narrativa.

6. JUIZO DISTRICTAL DO CIVEL E DO CRIME DO MUNICÍPIO DE GARIBALDI. Processocrime n. 1009 - P. C. (APRS - maço 30 - est. 29 - ano 1909).

7. "Relatório Médico Legal dos Drs. João Pitta Pinheiro e Antonio Carlos Penafiel, em 10 de maio de 1911 - Gabinete Médico Legal da Chefatura de Polícia do Estado do Rio Grande do Sul”. JUIZO DISTRICTAL ... Processo-crime n. 1009..., op. cit.

8. “Carta aos dottores”. HOSPÍCIO SÃO PEDRO. Prontuário n. 38120..., op. cit. 


\begin{tabular}{lccccc|l}
$R \quad E$ & $V$ & I & S & A & \\
LATIN O A M ERIC AN A & \\
DE PSICO PATO LO GIA & \\
F U N D A M E N T A L & \\
ano VIII, & n. 1, mar/ 2005 & \\
\hline
\end{tabular}

\section{A escrita epistolar como documento médico}

São inúmeras as possibilidades interpretativas sugeridas por fontes tão inusitadas como as construídas por um desses estranhos sujeitos - chamados loucos - que raramente puderam dizer de si mesmos e foram ouvidos. Porém, uma delas - a interpretação médica -, alcançou a escritura, e a vida, daquela mulher - como de outros internos em instituições manicomiais - muito antes que ela despertasse o interesse da história disciplina. Certamente tal interpretação contribuiu fundamentalmente para a constituição da própria memória da vida de Pierina, bem como para que um dia ela se tornasse personagem histórica.

Para alienistas e peritos médicos que avaliaram Pierina, suas cartas - nunca enviadas a seus destinatários, e anexadas a seu prontuário - foram um locus privilegiado para a percepção dos “sintomas” de uma dada doença mental, posto que traziam nelas sinais desta. O Regulamento do Hospício São Pedro que vigorava na época em que Pierina por lá passou, deixava bem claro que "Nenhum escripto poder[ia] ser recebido ou enviado pelos enfermos sem prévia auctorisação dos médicos”. ${ }^{9}$ Esta prescrição, vigente em praticamente todos os grandes hospitais psiquiátricos brasileiros e estrangeiros, justificava-se plenamente no plano teórico do saber psiquiátrico. Na escrita dos tidos como "loucos”, os alienistas acreditavam poder perceber com mais clareza os sintomas da "doença" que os acometera. As histórias de algumas pessoas que foram submetidas a exames clínicos e periciais, analisadas por Engel (1995, p. 187-8), revelam, segundo a autora, “... a importância atribuída aos escritos dos observados pelos psiquiatras. (...) cartas pessoais, diários íntimos e, até mesmo, opúsculos, panfletos, livros, publicados ou inéditos, eram vistos pelos médicos psiquiatras e legistas como verdadeiros mapas da mina, cuja decifração viabilizaria a elaboração de diagnósticos seguros”.

Também Cunha (1986) refere que, juntamente com outras atividades que faziam parte da chamada "terapêutica moral" - a música, sessões de cinema, a leitura de livros ou jornais -, a correspondência dos internos no hospício do Juquery em São Paulo, na década de 1930, era submetida à censura. As cartas eram consideradas mais um “documento” médico e “anexadas aos prontuários dos internos como uma confirmação de seu estado mórbido e da necessidade de sua internação” (Cunha, 1986, p. 118). Esta foi, também, uma das primeiras leituras feitas sobre os “escritos” de Pierina, como se pode observar a seguir.

9. Cf. Art. 28. RIO GRANDE DO SUL. Secretaria dos Negócios do Interior e Exterior. Regulamento do Hospício São Pedro. Porto Alegre, 7 de fevereiro de 1903 (AHRS/CL 637). 
Alguns sinais tênues sugerem que a primeira carta escrita por Pierina, e retida no seu prontuário, foi dirigida ao Juiz Distrital de Garibaldi, responsável por seu processo. Apesar de não estar datada, referências a acontecimentos tais como a lembrança do dia em que foi avisada de que seria transferida da Santa Casa de Misericórdia para o hospício - indicam que tal carta tenha sido escrita ainda no calor de sua recente internação no hospício, em 5 de julho de 1909. Nesta carta, Pierina rememorou sua entrada no hospital, deixando claro que para lá seguiu após muita resistência e ao ser enganada pelo Chefe de Polícia que prometera enviá-la da Chefatura para uma cadeia "lá no Partenão”, um arrabalde da Capital onde estava localizado o hospício. Sua insistência em não ser levada para o hospício, dizendo não ser louca, suas acusações ao Chefe de Polícia que a enganara, as súplicas ao Juiz para que a colocasse na cadeia que era o lugar de uma “criminosa”, a tirasse do “inferno”, lugar onde "secome peior dos cachorros", onde "não se pode dormir pelos critos que os locos e as locas fazem”, sem dúvida, "saltaram aos olhos" dos doutores como "provas circunstanciais" de sua loucura. ${ }^{10}$

Certamente também foram vistos como indícios de um certo quadro doentio, o desejo - manifesto nas cartas que vieram depois - de "não voltar mais" para Garibaldi, para “as familhas”, de não "mais passar nem um dia de vida [com a] familha” e a narrativa de "todo ho que t[inha] pasado neste triste mundo", na qual evidenciava dificuldades de toda sorte. Neste sentido, Pierina rememorou nas cartas as imensas dificuldades econômicas que cercaram sua vida e a de seus familiares. Realidade conhecida da comunidade de imigrantes italianos e seus descendentes que se fixaram na serra gaúcha desde meados do século XIX assumindo por vezes um aspecto idílico na narrativa de alguns cronistas - a pobreza, sem dinheiro para comprar "todo o que (...) farta”, adquiriu, nas palavras de Pierina, outro tom: foi um dos grandes responsáveis por seu sofrimento e sua perturbação. ${ }^{11}$

Em sua carta endereçada aos doutores do Hospício São Pedro, quando relatou que até a idade de 24 anos passou uma "vida regular trabalhando dia e noite para poder viver, de dia narosa de noite, trabalhava [fazendo] transa de chapeos", ${ }^{12}$ Pierina evidenciou as dificuldades de sobrevivência das comunidades encravadas nos lugarejos distantes do interior sul-riograndense. Os imigrantes e seus descendentes dedicados a uma agricultura de subsistência, condicionados

10. “Carta ao Juiz de Garibaldi”. HOSPÍCIO SÃO PEDRO. Prontuário n. 38120..., op. cit.

11. “Carta de Pierina à mãe”. HOSPÍCIO SÃO PEDRO. Prontuário n. 38120..., op. cit.; “Carta aos dottores”..., op. cit.

12. "Carta aos dottores”..., op. cit. 


\begin{tabular}{lccccc|l}
$R \quad E$ & $V$ & I & S & A & \\
LATIN O A M ERIC AN A & \\
DE PSICO PATO LO GIA & \\
F U N D A M E N T A L & \\
ano VIII, & n. 1, mar/ 2005 & \\
\hline
\end{tabular}

ao resultado de uma safra nem sempre boa ou ao problema do escoamento da produção por caminhos precários quando a colheita era abundante, tinham em atividades como o artesanato em palha de trigo ou o trabalho como jornaleiros na construção de estradas, uma das alternativas de sobrevivência. Porém, nem mesmo estas alternativas bastavam nas épocas de maior crise.

As crises de subsistência tinham motivos vários, como as intempéries e a infestação de pragas que acabavam com as colheitas, ou mesmo a infertilidade da terra causada pelo uso ininterrupto, pela ausência de técnicas apropriadas de desmatamento e cultivo. Acreditando-se no que escreveu Pierina, esta era a situação vivida por sua família em 1909, pois - após “34 anos que se trabalhava” - o pedaço de lote que possuíam era já uma “terra velha” e que “não da[va] mais nada”. O parcelamento constante de lotes pequenos por questões de herança foi outro motivo a contribuir para aumentar as dificuldades econômicas de famílias - como a de Pierina - já imersas em situação de pobreza desde sua saída da Itália em busca do eldorado em terras brasileiras. No caso específico da família Cechini, que em 1908 possuía apenas 1/4 de terra - cerca de 6,25 hectares -, dividi-la entre os herdeiros (ou seja, os filhos "varões”) mesmo que fossem poucos, agravava a situação de penúria. Para as mulheres - como Pierina e suas três irmãs mais velhas -, excluídas da divisão da terra e a quem cabia apenas "um dote em dinheiro e objetos - o enxoval - que não tinha nenhuma relação proporcional com o valor da parte que, legalmente, lhes corresponderia”, a situação era mais complicada (Santos, 1978, p. 51). Em sua carta aos “dottores” Pierina - referindo-se às motivações que a levaram ao ato criminoso -, refletiu sobre o que possivelmente aconteceria com ela depois da morte de seus pais, o que parece confirmar a tradição da exclusão das mulheres de qualquer herança: “... eu tinha de ir com toda aminha trosa a pedir esmola (...), eu lhe garanto que isto de pois da morte dos meus paes, isto tudo ma aconte sia, porque, eu não, tenho, nem terra, nem casa nem nada (...)" ${ }^{13}$

Parece ter sido, em princípio, tal realidade ou as interpretações que construiu dela, o que motivou o funesto pensamento de Pierina numa segundafeira, princípio do mês de agosto de 1908. Enquanto lavava a roupa de seu marido e o resto da roupa que estava em péssimas condições, descreveu em sua carta, ter sido tomada por um pensamento: “... me veio, este pençamento, não temos nada pra vestir e nada pra comer, somos todo treis sem ropa, estes dozentos mil reis que temos, comprando, todo o que nos farta não sega nois temos de morer de fome, por que semos muito pobre...”. ${ }^{14}$

13. Idem.

14. Idem. 
A partir deste momento, Pierina mergulhou num processo intenso de sofrimento que num período de aproximadamente nove meses fez com que, gradualmente, ela atingisse um estado que em nada lembrava as "gordas e coradas imigrantes italianas e suas descendentes” de que nos falam os cronistas da colonização. Descrevendo um processo no qual tentara matar-se diversas vezes e cujo ápice foi a morte da filha, Pierina fez aflorar em sua narrativa as motivações: a da pobreza, como se viu acima, mas também as afetivas, como “desgostos” com o marido ou com o próprio pai.

Antonio, o pai de Pierina, é figura central em suas rememorações, aparecendo sempre relacionado às dificuldades financeiras e à situação de extrema pobreza em que vivia. Em 1905, quando do “arranjo” de casamento de Pierina com o jovem Giacomo, o pai permitira que os recém-casados morassem em sua casa, rompendo com a tradição local de que as noivas é que passavam a residir na casa dos pais dos noivos. A contrapartida por parte dos noivos seria o amparo a Antonio em sua velhice, pois este já tinha, na época, cerca de 71 anos. Além dos cuidados cotidianos que os filhos deveriam devotar aos seus pais idosos conforme preceitos morais compartilhados pela comunidade dos imigrantes italianos e seus descendentes brasileiros -, a contribuição que parece ter sido exigida de Pierina e seu esposo, estava diretamente ligada à capacidade geradora de renda que ambos possuíam, pois como afirmou a narradora em sua carta aos “dottores", o pai se apropriava de todo dinheiro ganho pelo novo casal, dando a estes apenas alguns réis por mês. A justificativa usada pelo pai para ficar com todo o dinheiro ganho era a necessidade de comprar comida, escreveu Pierina. É provável que isto fosse realmente necessário nessa época, pois como vimos acima, a terra esgotada por motivos vários nem sempre gerava os frutos necessários à sobrevivência de quem dela dependia.

Rompendo assim com alguns costumes locais, pois o noivo não possuía um pedaço de terra ou uma casa para morar com sua esposa, Pierina casou-se com Giacomo com a "tenson de compagar o (...) marido ate ho dia da minha morte”. Pensava, narrou ela em sua carta aos doutores, em ter uma vida feliz, porém, tornou-se “a mais in felizes de todos os (...) irmães”. ${ }^{15}$ No princípio da vida de casados, o marido começou a trabalhar na roça fazendo os trabalhos mais necessários (como limpar e preparar o solo para o plantio), depois foi trabalhar na estrada de ferro para poder pagar dívidas antigas (com moradia) e as que adquirira com o casamento (o vestido da noiva e as alianças). Repetir-seia, a partir de então, uma rotina de sobrevivência: o trabalho na roça para garantir parte da subsistência e a volta para o trabalho na estrada de ferro para completá-

15. Idem. 
la. Poupar, para adquirir outros bens que não a comida, era um sonho difícil de realizar, pois Giacomo e Pierina entregavam tudo o que ganhavam para o pai desta, conforme havia sido estabelecido quando do casamento.

Era também difícil conseguir dinheiro necessário para compras pessoais, como roupas, remédios etc., pois o pai entregava ao marido de Pierina apenas mil reis a cada domingo. Esta quantia, escreveu Pierina, não era suficiente nem mesmo para as despesas já estabelecidas como corriqueiras por seu marido, como o pagamento da mensalidade de sócio da Sociedade Italiana de Mútuo Socorro, a manutenção do cavalo que possuía ou aquelas ligadas à sociabilidade masculina, como o "visio de pitar" e de fazer "um pouco de festa". Pierina contou que Giacomo, nos períodos em que permanecia em casa, nos intervalos dos trabalhos de construção de estradas, aos "sabado, ia fazer um pouco de festa ia cortar a barba, vinha bebedos as 11 ou ameia noite”. A sociabilidade na bodega, constituía um espaço e um momento não partilhados entre os homens e as mulheres nas antigas colônias e, principalmente, um tempo de não produção, que, parece, gerou inúmeros conflitos familiares, como indicam as pistas deixadas por Pierina: “O meu marido, a vida delle era esta, se a sema, era todos dias de festa, elle era capaz, de passar a sema intera nas vendas, e quando vinha, a qual quer, horas da noite, bebedos, como um, porco, elle, lansava tudo, e assim, eu ficava, muito braba eralhava com elle, se lhe dizia semos tão pobre, e tu sempre bebedo a eta maneira...”. ${ }^{16}$

As dificuldades - em relação à pobreza, ao relacionamento com o pai ou ao casamento - invocadas por Pierina, como motivadores de sua recusa em viver e da idéia de matar a filha, não foram, no entanto, consideradas pelos peritos que procederam ao exame médico-legal como suficientes para um abalo moral ou para jogá-la no quadro depressivo em que entrara. Fora, portanto, "sem motivo suficientemente razoável, que nasceu no cérebro de Pierina, a idéia de matar sua filhinha, que, sem que ela a pudesse dominar, constituiu-se, embora, consciente disso, num pensamento parasitário", anotaram os médicos no relatório pericial. A fraqueza de caráter, típica dos degenerados, dos psicopatas constitucionais, percebida em Pierina foi - segundo os peritos - o que de fato permitiu a instalação da "sua obsessão, ilegítima e fora do natural”, pois haveria, “obsessões legítimas e naturais”. ${ }^{17}$ Naturalmente, os médicos não se preocuparam em nomear tais “obsessões legítimas”.

Ainda que da história pregressa daquela mulher os peritos soubessem pouco, haviam se esforçado em reunir todos os dados que conseguiram obter

16. Idem.

17. “Relatório Médico Legal dos Drs. João Pitta Pinheiro e Antonio Carlos Penafiel...”, op. cit. 
por meio de testemunhos, das cartas escritas por ela ou de suas "palestras” com eles, para construir o perfil "anormal” da denunciada, afirmaram em seu relatório. Tinham tido conhecimento, por exemplo, que Pierina "sempre fo[ra] de caráter um pouco instável”, instabilidade esta que se revelara "bastante por ocasião do seu casamento”, pois "ora parecia a mais interessada neste, ora considerava-se contrariada, sendo forçada ao matrimônio por seus pais”. A tais "vacilações”, teria ainda vindo somar-se a transformação ocorrida no "estado mental ordinário" de Pierina, por ocasião de sua gravidez, quando "tornou-se um pouco triste e nervosa, chorando muito”. A amamentação, os primeiros trabalhos da maternidade e as dificuldades materiais e morais, que pode ter um casal pobre de colonos, contribuíram - segundo os médicos - para que se pronunciasse o caráter depressivo de Pierina, que não teve energia moral para se conformar com sua situação e, tornou-se “de mau humor, queixosa da sua indigencia, rebellada contra o seu marido e o casamento, a quem tudo attribuía, irrascível com todos os seus. E, assim raciocinando, chegou a conclusão que não valia a pena viver, nem deixar crescer sua filhinha na mesma infelicidade, para que mais tarde não conhecesse a desgraça e miséria de sua mãe.”18

A avaliação da estrutura moral de Pierina indicava claramente, aos olhos dos médicos, um indivíduo de caráter fraco ou pervertido - caráter típico dos degenerados. Assim, quando Pierina aliou em suas cartas, as queixas sobre a condição de quase indigência em que se achavam ela e os seus - nomeadas pelos médicos como "dificuldades materiais que pode ter um casal pobre de colonos" -, o desagravo de ter um marido bêbado e que gastava o pouco que tinham nas bodegas - queixa interpretada pelos peritos como "rebeldia contra o marido e o casamento a quem tudo atribuía” -, ainda a vergonha de ser conhecida como "a louca” e ver sua filha crescer como "a filha da louca” - estigma constituído a partir do momento em que seu sofrimento e sua perturbação tomaram ares de “coisa pública” -, os médicos puderam invocar a mística de um amor materno inato à natureza feminina para comprovar o caráter distorcido de Pierina.

Segundo os médicos “A idéia duma mãe matar seu próprio filho não pode ser legítima e natural, embora a justifique ou procure justificar 'pelo desejo de não o ver mais tarde desgraçado’”. A “obsessão” de Pierina estava caracterizada para os médicos, pois haviam averiguado junto à sua família e a ela mesma, que há muito tempo ela desejava praticar o ato criminoso. Apenas o evitara, as ações da família que, de certa forma, relutara contra o estado mental de Pierina, afastando dela a menina em alguns momentos. ${ }^{19}$

18. Idem.

19. Idem. 


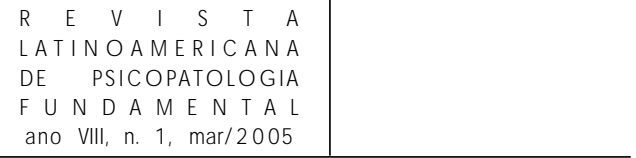

Ao pensar que as representações que construíam dos loucos eram imagens “puras, eternas, universais ou simplesmente verdadeiras em si mesmas”, os peritos - dublês de alienistas ${ }^{20}$ - simplesmente reiteraram exatamente o que faz adoecer: “calar a diferença, calcificar o existente, impotencializar a vida, travar a processualidade do ser, brecar a história” (Rolnik apud Perelmutter, 1997, p. 60). E, assim, leram nas cartas de Pierina os sintomas de uma doença mental. Segundo os legistas, de acordo com o alienista chefe do hospício, ${ }^{21}$ a paciente apresentava "uma perversão do instinto materno" peculiar à "degeneração inferior" de que era portadora, além de "estigmas de ordem depressiva”, próprios a uma "psychose hystero-neurasthenica”. Ela era, sem dúvida, portadora de uma "moral insanity”, como diziam os ingleses, ou seja, uma "loucura moral”, na tradução dos alienistas tupiniquins. ${ }^{22}$

Esse diagnóstico, segundo os médicos, fora fruto de uma observação demorada de meses, confirmando o que já havia sido “adiantado” pelos próprios legistas no primeiro "olhar" lançado a Pierina, quando esta ainda estava internada na Santa Casa e eles realizaram - ao que parece - apenas duas breves visitas, redigindo então um primeiro relatório que justificava a internação da paciente no hospício. ${ }^{23} \mathrm{O}$ diagnóstico final fora em grande parte resultado, segundo estes, das "palestras" que tiveram com ela e da "tradução" - da instabilidade de seu psiquismo - nas "cartas" que escreveu. ${ }^{24}$ Cartas estas que os alienistas tiveram - sob seu ponto de vista - a "sabedoria" de guardar junto aos documentos oficiais da passagem de Pierina pelo hospício.

20. O Código de Processo Penal do Rio Grande do Sul de 1898, indicava a preferência pelo diretor ou médico assistente de um hospital de alienados na realização de exames periciais, mas eram os médicos do Gabinete Médico-Legal da Chefatura de Polícia - nesse período histórico -, que procediam a grande parte dos exames desta natureza.

21. É interessante observar que, a despeito de não existirem "observações” registradas pelo médico do hospício no prontuário de Pierina - o que necessariamente não significa que elas não foram feitas -, seu diagnóstico - este sim registrado - coincidia com o elaborado pelos peritos da Chefatura de Polícia.

22. "Relatório Médico Legal dos Drs. João Pitta Pinheiro e Antonio Carlos Penafiel...”, op. cit.

23. "Atestado médico-legal dos Drs. João Pitta Pinheiro e Antonio Carlos Penafiel, em 5 de julho de 1909 - Gabinete Médico Legal da Chefatura de Polícia do Estado do Rio Grande do Sul”. JUIZO DISTRICTAL ... Processo-crime n. 1009..., op. cit.

24. “Relatório médico-legal dos Drs. João Pitta Pinheiro e Antonio Carlos Penafiel ...”, op. cit. 


\section{A escrita epistolar como documento histórico}

Para o historiador, as "escrituras ordinárias” ou "escritos sem qualidade” dos internos em hospitais psiquiátricos, têm significados diferentes do que lhes deu o saber médico.

Reconstituir algo das múltiplas dimensões de uma vida, situada num campo de possibilidades históricas - através do garimpo em sinais, vestígios e pistas tênues deixados pela escritura de Pierina -, é uma forma instigante de integrar, na "globalidade do processo histórico de seu tempo" (Dias, 1984, p. 7), sujeitos durante muito tempo percebidos - tanto por parcelas significativas de seus contemporâneos quanto pelo próprio conhecimento histórico -, como "sem importância”: as mulheres, os loucos, as mulheres loucas... Resgatar a história desta mulher singular - utilizando-se de seus escritos como documentos preferenciais -, mostra quão amplas e diversas, conflitantes, tensas e controversas podem ser as dimensões e possibilidades de uma vida, constituindo-se numa contribuição na tarefa de desvelar como é múltiplo o social e quanto podem ser enganosas as impressões sobre a importância de certos sujeitos sociais (Wadi, 2002b). Outras interpretações de “identidades femininas” ou de processos e espaços singulares como os ocupados pelos tidos como loucos, "somente virão à luz na medida em que experiências vividas em diferentes conjunturas (...) forem gradativamente documentadas” (Dias, 1994, p. 374).

No caso de uma mulher, como Pierina, que foi em determinado momento de sua trajetória de vida tida como louca, tal posição fez "emergir (...) sobretudo os papéis informais, as improvisações, a resistência” (Dias, 1994, p. 374) de um sujeito em mutação ao viver - e nelas se configurar - experiências como a do crime, do sofrimento psíquico, da internação num manicômio. Quando se trata dos loucos, percebe-se claramente que somente uma atitude que recuse "suturar as questões de vida” - mesmo quando estas já se transformaram em memórias de vida, deixadas em testemunhos de próprio punho -, pode ter alguma chance de alcançar "problemas de vida” (Pelbart, 1995, p. 172).

A análise dos escritos demonstrou que, para Pierina - ainda que não racionalizasse ao extremo o seu ato de escrever -, colocar no papel, por "vontade própria de lembrar” ou incentivada por outrem, sua história de vida, pode ter proporcionado a "sensação catártica de botar para fora tanta coisa guardada, de exorcizar fantasmas do passado, matando-os de novo bem mortos no papel” (Arrigucci Jr., 1987, p. 68). Nesse sentido, sua rememoração foi “catártica”, adquirindo a função de uma “purgação” (Maluf, 1995, p. 32) pois, na mesma medida em que ela expressou nas cartas suas dores, tristezas, desgostos, ou seja, tudo aquilo que identificava como as “causas de sua desgraça”, também expiou 
a "culpa” que sentia por ter matado a filha. Além de tais aspectos, seus "escritos" trazem sinais significativos de um alívio que - a despeito de tudo - conseguiu sentir, especialmente porque o crime cometido acabou por levá-la para longe do que gerava seu sofrimento: o pai, o marido, o trabalho árduo, a vizinhança e seus comentários... Foi assim também que, ao rememorar e escrever, Pierina fez uma espécie de "ajuste de contas” com seu passado, constituindo-se, esta mágica da memória, numa experiência purificadora, quiçá libertadora.

Na análise da documentação produzida por Pierina é bastante visível, também, que ela não registrou uma história - a sua história - como uma escritora o faria, experimentando o fascínio da imagem, fingindo-se outra ou fingindo emoções alheias. Escreveu como escrevente, e, neste sentido, seus escritos, sem nenhuma preocupação literária, tiveram por certo um claro fim: “testemunhar, explicar, ensinar” (Barthes, 1982, p. 35). Ela queria, em primeiro lugar, aos “doutos" "esplicar todo ho que t[inha] pasado neste triste mundo", como disse anteriormente. Mas queria também “que estas cartas, fosse, tudo, num jornal para tudo o povo, saber (...) este tudo que passei na minha vida e o que tenho de passar”. ${ }^{25}$

Mesmo ambicionando que todos soubessem do que se passava consigo dos sábios ao povo - Pierina talvez tenha acreditado que seus escritos estivessem a "salvo de ambigüidades". Neste sentido, conforme Barthes (1978, p. 36) seu "projeto de comunicação" foi totalmente "ingênuo", como o de todo escrevente que acredita ser a explicação contida em seus "escritos”, irreversível ou incontestável. Crença esta paradoxal ao extremo, em se tratando de uma interna num hospício do início do século XX onde, tudo o que era escrito pelos “ditos loucos”, podia ser lido - como de fato o foi no caso de Pierina - como sintoma de uma dada doença.

\section{Referências}

ArRiguCCi Jr., Davi. Móbile da memória. In: Enigma e comentário: ensaios sobre literatura e experiência. São Paulo: Companhia das Letras, 1987.

Artières, Phillippe. Arquivar a própria vida. Estudos históricos, Rio de Janeiro, v. 11, n. 21, p. 9-34, 1998.

Barthes, Roland. Crítica e verdade. São Paulo: Perspectiva, 1982.

25. “Carta aos dottores”..., op. cit. 
Costa, Rovílio. Valores da imigração italiana cem anos após. In: INSTITUTO SUPERIOR BRASILEIRO-ITALIANO DE ESTUDOS E PESQUISAS. Imigração italiana: estudos. Porto Alegre, EST/Caxias do Sul, UCS, 1979.

Cunha, Maria C. P. O espelho do mundo: Juquery, a história de um asilo. Rio de Janeiro: Paz e Terra, 1986.

Cunha, Maria T. S. Por hoje é só... Cartas entre amigas. In: Bastos, Maria H. C.; Cunha, Maria T. S.; Mignot, Ana C. V. (orgs.). Destinos das letras: história, educação e escrita epistolar. Passo Fundo: UFP, 2002. p. 181-204.

Dias, Maria Odila L. S. Quotidiano e poder em São Paulo no século XIX - Ana Gertrudes de Jesus. São Paulo: Brasiliense, 1984.

Novas subjetividades na pesquisa histórica feminista: uma hermenêutica das diferenças. Revista Estudos Feministas, Rio de Janeiro, número especial, p. 373-82, $2^{\circ}$ sem./1994.

Engel, Magali. A loucura na cidade do Rio de Janeiro: idéias e vivências (1830-1930). 1995. Tese (doutorado em História). IFCH/Unicamp, Campinas.

Maluf, Marina. Ruídos da memória. São Paulo: Siciliano, 1995.

Pelbart, Peter P. Os loucos trinta anos depois. Novos Estudos CEBRAP, São Paulo, n. 42, p. 171-6, jul/1995.

Perelmutter, Daisy. A história oral e a trama sensível da subjetividade. 1997. 113p. Dissertação (mestrado em Psicologia Social). Programa de Pós-Graduação em Psicologia Social, Pontifícia Universidade Católica de São Paulo.

Santos, José V. T. Colonos do vinho. Estudo sobre a subordinação do trabalho camponês ao capital. São Paulo: Hucitec, 1978.

ScotT, Joan. A invisibilidade da experiência. Projeto História, São Paulo, n. 16, p. $297-$ 325, fe/1998.

WADI, Yonissa M. Palácio para guardar doidos: uma história das lutas pela construção do hospital de alienados e da psiquiatria no Rio Grande do Sul. Porto Alegre: Editora da Universidade /UFRGS, 2002a.

Louca pela vida: a história de Pierina. 2002b. 342 p. Tese (doutorado em História). Programa de Pós-Graduação em História, Pontifícia Universidade Católica de São Paulo. 